\title{
Prediction of interwell connectivity and interference degree between production wells in a tight gas reservoir
}

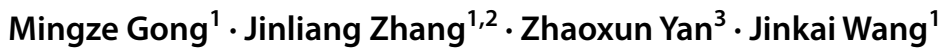

Received: 13 September 2020 / Accepted: 20 March 2021 / Published online: 29 May 2021

(c) The Author(s) 2021

\begin{abstract}
Sulige gas field has poor reservoir physical properties and strong heterogeneity. The existing development well pattern is difficult to realize the overall effective production of reserves, especially in block SuX. Therefore, this paper takes SuX block in the east of Sulige as an example to describe an effective method suitable for the development of well pattern in this area. Combined with logging and production data, the connectivity of gas wells in X infill area in the east of Sulige is determined from the aspects of pressure, sand body, logging, performance and well test. By using the method of dynamic and static analysis, the connectivity between wells of main gas reservoir is judged. Through the analysis of flow unit, the discharge area and the stable value of well-controlled reserves are determined. The degree of interference determined by curve fitting and the distribution characteristics of sand bodies are comprehensively analyzed. A new oil well interference degree model defined by mathematical expression of production is established. The interference degree is quantified by gas production through numerical simulation. Based on the comprehensive analysis of the connectivity, interference degree and other factors in the area, it is determined that $500 * 600$ well pattern is a reasonable well pattern in SuX block, and the interference degree is about $20 \%$. Based on the analysis of the connectivity between wells and the interference degree between production wells in SuX block, the distribution and connectivity of sand bodies in tight sandstone gas field under complex geological conditions are determined. It provides a reasonable basis for the network encryption development of tight sandstone gas in this block. It provides a powerful technical support for the efficient development of different tight gas reservoirs in Sulige area.
\end{abstract}

Keywords Sulige gas field · Performance analysis · Numerical simulation · Interwell connectivity $\cdot$ Interference degree . Well pattern

\section{Introduction}

Sulige gas field is a typical tight gas field, and its low pressure and low permeability are more prominent in the East Sulige area than in the whole area. Unlike conventional sandstone reservoirs, because of the low permeability, strong

Jinkai Wang

wangjk@sdust.edu.cn

Jinliang Zhang

jinliang@bnu.edu.cn

1 College of Earth Science and Engineering, Shandong University of Science and Technology, Qingdao 266590, China

2 Faculty of Geographical Science, Beijing Normal University, Beijing 100875, China

3 The Fourth Gas Production Plant, Changqing Oilfield Branch, PetroChina, Xi'an 710021, China heterogeneity and wide range of well control, dense well network is usually used for development (Mattar and Anderson 2003; Fan et al. 2011; Guang et al. 2019). The development of dense well network often leads to interwell interference, which seriously affects the development of natural gas and the economic benefits of gas field. The research and development practice results of tight sandstone gas recovery at home and abroad show that well pattern density is the key factor affecting the reserve production and recovery of tight sandstone gas field (Amini and Valkó 2010; Guo et al. 2014; Zhi et al. 2017). He et al. (2013) and others have carried out the research on the well pattern well pattern technology of largescale tight sandstone gas field in Sulige from the overall development and oil recovery of the gas field. It is believed that the well pattern of Sulige gas field can accept some degree of interwell interference (Ren et al. 1997; Wang et al. 2011; He et al., 2012; Zhu 2015). If the control reserves of single well are insufficient, it is difficult to fully utilize

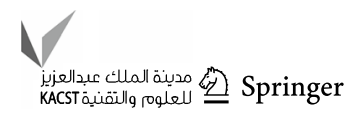


regional reserves, which leads to low final recovery of gas field; however, if the well network is too dense, the interference between wells will tend to be serious, and the recovery rate will be improved with the decrease of return (Mattar and Mcneil 1998; Li et al. 2008; Zhang 2010). Therefore, a reasonable well pattern is the key to the development of the region.

The existing $600 \mathrm{~m} \times 800 \mathrm{~m}$ well pattern is mainly developed in Sulige area, which has low control over regional reserves and low recovery. In order to improve the producing degree of gas reservoir and the recovery rate of gas field, the infilling of vertical well pattern is the most effective means. In the existing well pattern development research of Sulige gas field, the well pattern infilling mainly needs to consider the deployment of infill area and the infill method of infill area. The mainstream well pattern development method relies on the reserve abundance, which plays an important role in the deployment of well pattern in the early stage of exploration and development. However, due to the strong heterogeneity of tight gas reservoir and complex geological information, low production gas wells often appear in some high reserves kurtosis infill areas in the later stage of gas reservoir development, which leads to the infill well pattern recovery inconsistent with expectations. In addition, the reservoir physical properties of block X in Sulige east area are lower than other blocks in this area, and the general well pattern is not suitable for this area. In this paper, the dynamic and static analysis method is used to determine the connectivity and interference between wells, determine the seepage boundary of gas wells, and determine the complex geological information of tight gas wells. It provides guidance for the reasonable optimization of well pattern.

First, in the first section, we analyze the connectivity of regional wells, the rationality of existing well pattern and the feasibility of regional infill through static and dynamic methods. In the second section, the seepage law of gas well and the controlled reserves and area of single well are understood through the analysis of seepage law. Based on the dynamic data, the interference of existing well groups is analyzed. Combined with the analysis of connectivity in the first section, the distribution law and size of effective sand body are simulated. Finally, the relationship between interference degree and well pattern is calculated by numerical simulation, and the reasonable well pattern density is finally deduced.

\section{Judge interwell connectivity}

Interwell connectivity is the focus of dynamic analysis of oil and gas reservoirs, which is mainly studied from two aspects of static and dynamic reservoir. Static method mainly includes interwell horizon correlation; dynamic identification method is well test data analysis. The study of interwell connectivity can be used to study the heterogeneity between reservoirs, and lay a foundation for the establishment of fine geological model and the optimization of gas field development well pattern (Zhang 2003).

\section{Regional pressure analysis}

Although there are few fault structures in Eastern Sulige area, the vertical and horizontal combination of different types of fluvial strata are quite different. The same well group is not necessarily controlled by the same pressure source. The static pressure gradient analysis method is usually used to analyze the pressure system of gas reservoir (He et al. 2003). Based on the well test data, the relation curve between the original formation pressure of each well and its corresponding middle depth is drawn in the rectangular coordinate system. The connectivity can be determined by having good linear law and the same slope. For example, SDJX-1 and SDJX-2 in the three infill wells in the south of SuX have the same pressure gradient, so it can be determined that the two wells may be connected (Fig. 1).

For the low-permeability gas reservoirs that have been put into operation, due to the difference of permeability between the boundary and the wellhead, the initial pressure of the gas well drops rapidly, the bottom hole flow pressure and the formation pressure drop are not synchronous, and the gas well is in an unstable flow state for a long time (Fang et al. 2009). When a gas well enters the quasi stable seepage state, if the wells are connected, the pressure of the undeveloped wells will decrease with the exploitation of the adjacent wells, that is, for each target well with the same production horizon in a certain area, the initial formation pressure of the new production well is compared with the average initial formation pressure of the adjacent wells in the area. If the initial formation pressure is obviously lower than that of the adjacent

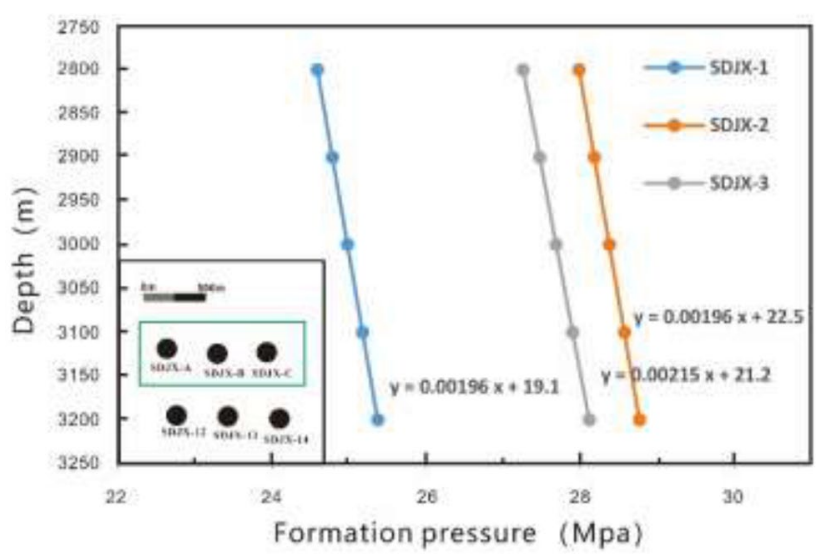

Fig. 1 Pressure gradient distribution comparison chart 
wells, the well may have been affected by the adjacent wells on the impact of production.

Take well group SD x-A as an example. The infill wells around well group $\mathrm{x}-\mathrm{A}$ in the east of Jiangsu are far lower than the average static pressure and casing pressure in the test area. Mainly from two early production wells SDX-B and SDX-C put into operation in 2011. (Current cumulative production: $3551 \times 10^{4} \mathrm{~m}^{3}, 3180 \times 10^{4} \mathrm{~m}^{3}$ ) The long-term production of the two wells leads to the loss of formation pressure, so these infill wells SDJX-A and SDJX-B decrease with lower initial pressure (Table 1).

\section{The continuity of sand bodies}

To observe the distribution and change of sandbody. The reservoir continuity can be found by making connected wells'

Table 1 Initial formation pressure information of well group SDX-A

\begin{tabular}{lll}
\hline Well number & $\begin{array}{l}\text { Formation pressure before } \\
\text { production (MPa) }\end{array}$ & $\begin{array}{l}\text { Casing pressure } \\
\text { before production } \\
(\mathrm{MPa})\end{array}$ \\
\hline SDJX-A & 24.12 & 17.85 \\
SDX-B & - & 22.31 \\
SDJX-B & 23.69 & 18.58 \\
SDX-C & - & 21 \\
\hline
\end{tabular}

profile for 5 wells in SDX-A well group from north to south and from east to west; taking SDX-A well as the center, five wells are not more than $800 \mathrm{~m}$ apart and the reservoir is continuous. Geological analysis shows that the reservoir is developed in this area, and the production layers of each well are mainly He_8 and Shan_1. Among them, the effective thickness of each well section is unevenly distributed, with the exception of Shan_1-2 of well SDX-B and Shan_1-1 of well SDJX-A, which are $10.9 \mathrm{~m}$ and $10.8 \mathrm{~m}$ respectively. The effective thickness of most of the layers is relatively small, which is $1.5-5 \mathrm{~m}$. The perforation thickness is $2-4 \mathrm{~m}$, and the perforated well sections are all on the production layer, so there is the possibility of communication after fracture. The regional sand bodies are developed in the north-south direction, and in the north-south and east-west longitudinal directions, the sand bodies are superposed, and the probability of connectivity between reservoirs is high (Fig. 2).

\section{Logging data analysis}

It can be found from the interpretation data of logging results (Table 2). Except for the small difference in porosity, other values have different degrees of difference, excluding factors such as equipment difference and human error. The reason for the difference in well group data may be the selection of measuring well section and the difference in production
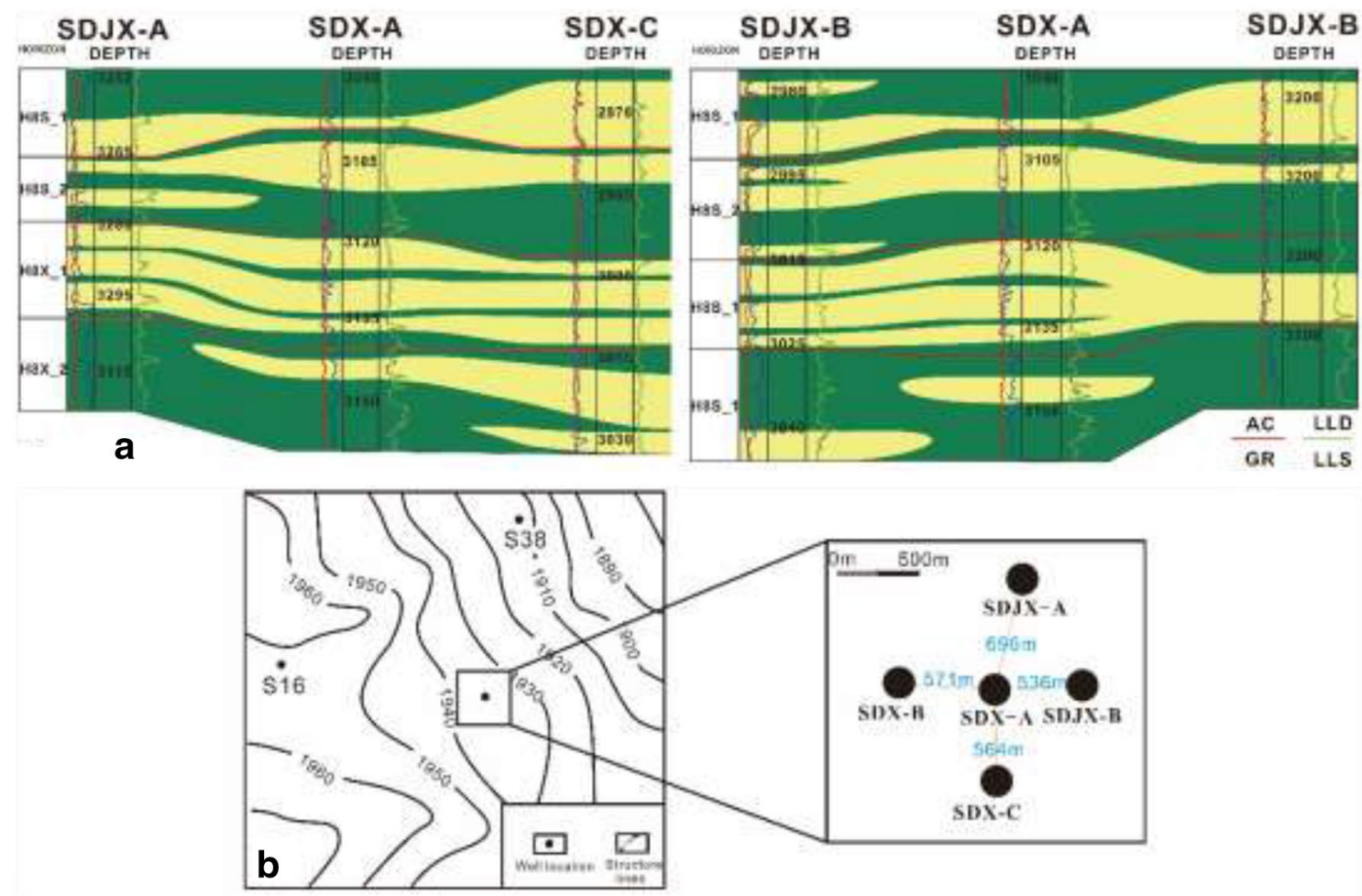

Fig. 2 Well connection profile of well group X-A in Sudong (a) well location map of well group X-A in Sudong (b) 
Table 2 SD X-A Well group logging data

\begin{tabular}{lclllll}
\hline Well number & Well depth $(\mathrm{m})$ & Thickness $(\mathrm{m})$ & $\begin{array}{l}\text { Total } \\
\text { porosity } \\
(\%)\end{array}$ & $\begin{array}{l}\text { Gas satu- } \\
\text { ration }(\%)\end{array}$ & $\begin{array}{l}\text { Matrix perme- } \\
\text { ability }(\mathrm{mD})\end{array}$ & $\begin{array}{l}\text { Sandstone } \\
\text { content } \\
(\%)\end{array}$ \\
\hline SDX-A & $3103.4-3219.8$ & $1-7.6$ & 10.45 & 60.4 & 0.76 & 94.3 \\
SDX-B & $2997-3108$ & $2.3-10.9$ & 9.04 & 60.52 & 0.43 & 91.2 \\
SDX-C & $300.8-3081.9$ & $1.6-5.3$ & 10.89 & 54 & 0.38 & 91 \\
SDJX-A & $3265.9-3358.1$ & $1.4-10.8$ & 8.64 & 46.06 & 0.568 & 84.86 \\
SDJX-B & $3018-3083$ & $1.5-4.3$ & 10.99 & 49.2 & 0.98 & 87.9 \\
\hline
\end{tabular}

horizon. The difference of sand shale content in different wells is also one of the reasons.

\section{Dynamic feature analysis}

Well SDX-A is a development well in 2011, which was put into production on November 5, 2011. Production horizon of gas well is He_8, Shan_1. The dynamic classification is class I well. At present, the daily gas production is $1.0 \times 10^{4} \mathrm{~m}^{3} / \mathrm{d}$, casing pressure is $7.37 \mathrm{MPa}$, and the cumulative production is $3847 \times 10^{4} \mathrm{~m}^{3}$. The well has a long production time and stable production, which is located in the regional center. Judge the connectivity of each well with this well as a reference. SDJX-B well is an infill well in Sudong block in 2017, which was put into production on November 11,2017 . The production horizon is He_8 down 1 Shan_1_2. At present, the daily gas production is $0.80 \times 104 \mathrm{~m}^{3}$, the casing pressure is $8.77 \mathrm{MPa}$, and the cumulative gas production is $156 \times 10^{4} \mathrm{~m}^{3}$. SDJX-A well was put into operation on September 20, 2017. The production horizon is He_8 lower 1 Shan_1_2. At present, the daily gas production is $1.25 \times 10^{4} \mathrm{~m}^{3}$, the casing pressure is $14.4 \mathrm{MPa}$, and the cumulative gas production is $172 \times 10^{4} \mathrm{~m}^{3}$.

The static pressure/casing pressure of SDJX-A and SDJX$B$ wells before well opening are lower than the average value of the block; on the production curve, there is certain pressure synchronization between the two wells (Fig. 3), and the pressure synchronization is mostly related to the production system. The lower opening pressure may be mainly
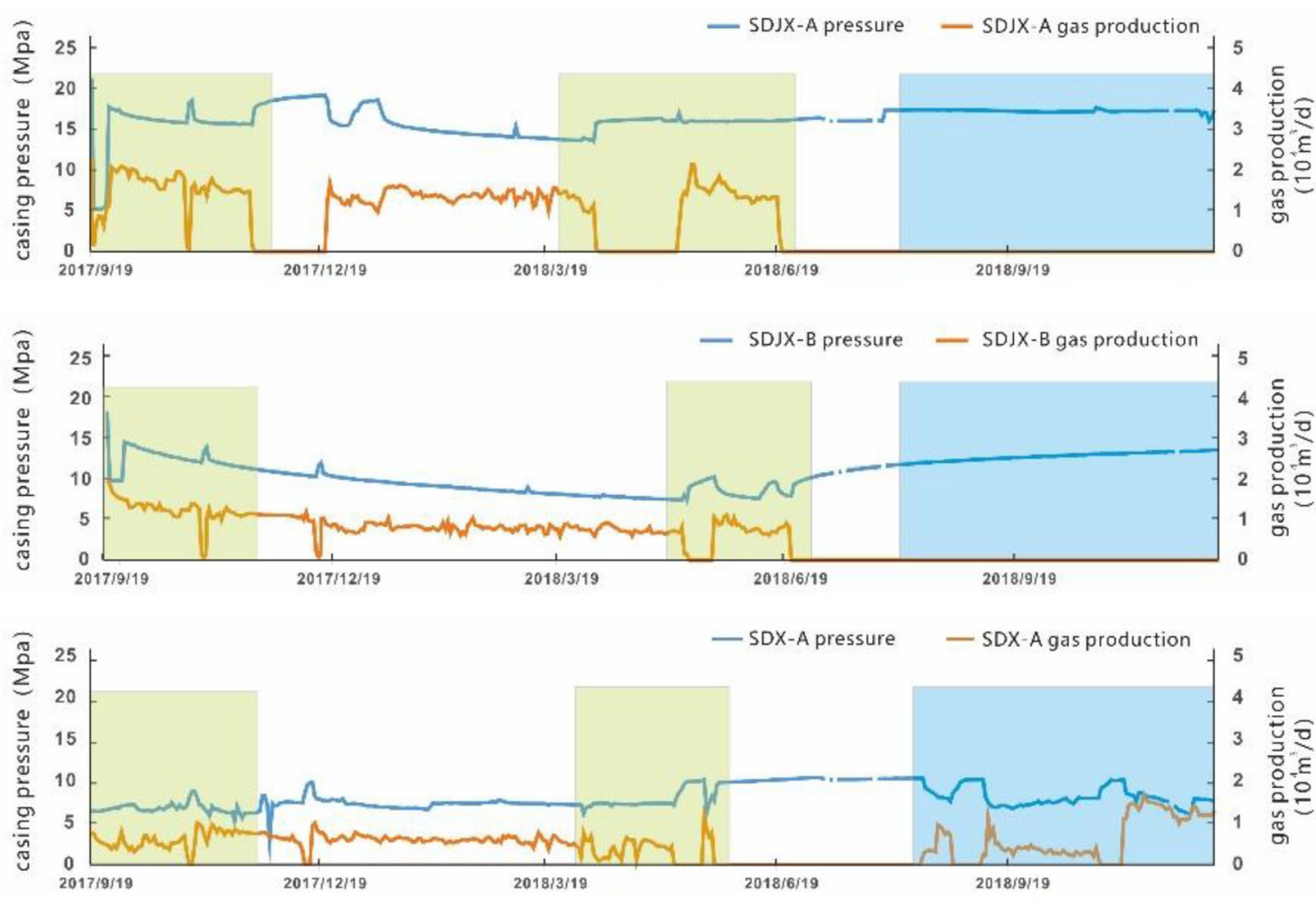

Fig. 3 Production curve analysis of infill well in well group SDX-A 
due to the formation pressure loss caused by the early production wells in the southeast. When SDJX-A and SDJX-B are shut down, the production fluctuation of well X-A does not change the pressure of the two wells. Moreover, due to the low production time and low dynamic well control area of the two infill wells, it can be judged that the connection probability of the three wells is low. SDX-B well was put into production on November 6,2011 . The production horizon is under $\mathrm{He} 8$, shan1-2. At present, the daily gas production is $0.45 \times 10^{4} \mathrm{~m}^{3}$, the casing pressure is $1.34 \mathrm{MPa}$, the cumulative gas production is $3138 \times 10^{4} \mathrm{~m}^{3}$, and the final cumulative gas production is predicted to be $3744 \times 10^{4} \mathrm{~m}^{3}$. SDX-C well was put into operation on December 31, 2008. The production horizon is He_8 lower $1, \mathrm{He} \_8$ lower 2 , and
Shan_1_3. At present, the daily production is $0.29 \times 10^{4} \mathrm{~m}^{3}$, the casing pressure is $3.01 \mathrm{MPa}$, the cumulative production is $1536 \times 104 \mathrm{~m}^{3}$, and the final cumulative production is predicted to be $1744 \times 10^{4} \mathrm{~m}^{3}$ (Fig. 4).

The production curves of well Sudong X-B and well Sudong X-A are similar. The two wells adopt similar production system, and the gas output is roughly the same, but the pressure curve matching is poor. The casing pressure of well Sudong X-B decreases rapidly, which is mainly caused by the difference of formation permeability. In the case of similar production, the pressure mutation of well Sudong X-B and well Sudong X-A is not synchronized with each other. The analysis shows that the probability of reservoir connectivity of the two wells is small, but both of them are disturbed to a certain extent, and the $\mathrm{X}-\mathrm{B}$ in Sudong may have interference with other gas wells.
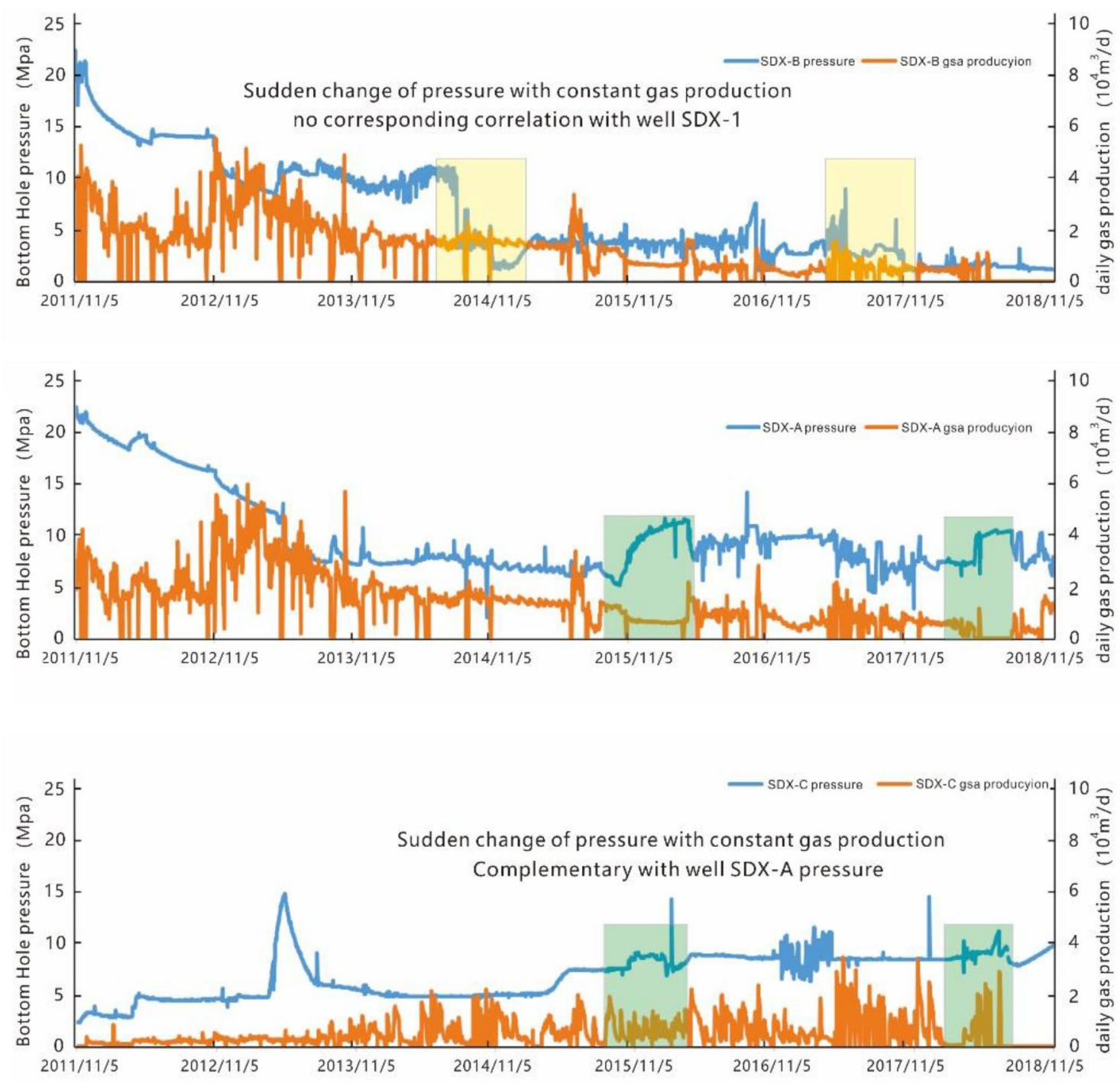

Fig. 4 Production curve analysis of well Sudong X-A and Sudong X-B 
However, the reservoir physical property of well X-C in Sudong is poor, and it has been in low-pressure production for a long time, but part of its pressure curve fluctuation is related to well X-A, which indicates that there is a certain connectivity between the two wells.

\section{Interference well test analysis}

Taking SDX-A well as an active well, Saphir software was used for interference test, analysis and test. Taking well spacing and permeability as main parameters, the time when the observation well saw $0.1 \mathrm{MPa}$ interference pressure drop was estimated. The interference model of SDX-A interference well group was established by referring to the well logging interpretation permeability of the active well and each observation well, and the time required for pressure drop was calculated by simulation. It can be seen that

Table 3 Time schedule for pressure drop of observation well $0.1 \mathrm{MPa}$

\begin{tabular}{llll}
\hline Well number & Distance $(\mathrm{m})$ & $\begin{array}{l}\text { Matrix } \\
\text { permeability } \\
(\mathrm{md})\end{array}$ & $\begin{array}{l}\text { Time required for } \\
\text { pressure reduction of } \\
0.1 \mathrm{MPa}(\mathrm{d})\end{array}$ \\
\hline SDJX-A & 696 & 0.57 & 54 \\
SDX-B & 571 & 0.43 & 46 \\
SDJX-B & 536 & 0.98 & 37 \\
SDX-C & 564 & 0.38 & 50 \\
\hline
\end{tabular}

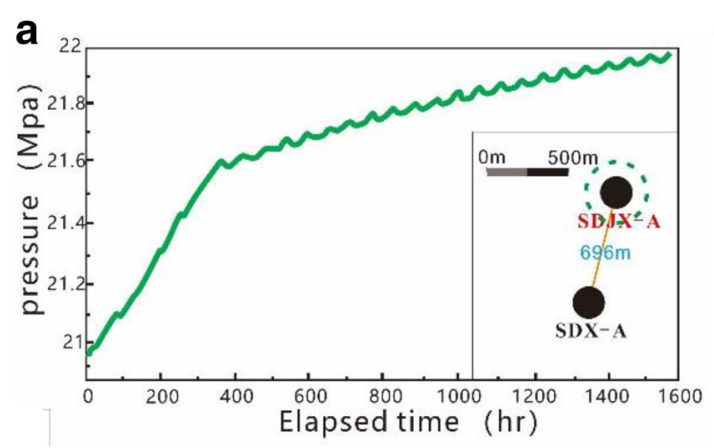

C

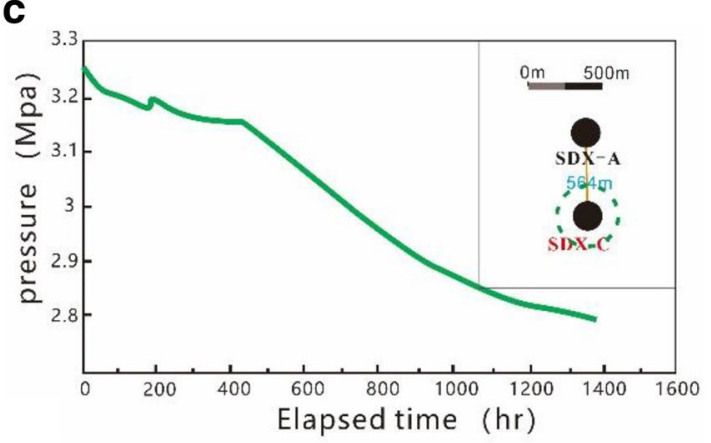

it will take a long time to observe the pressure change of each observation well even if the active well is produced at $1.0 \times 10^{4} \mathrm{~m}^{3} / \mathrm{d}$ (Table 3).

During the interference well test, the well $\mathrm{x}$-a produced at $1.0 \times 10^{4} \mathrm{~m}^{3} / \mathrm{d}$, and four observation wells were pressure tested. With the stimulation well production, the pressure drop was caused, and the influence of pressure gauge instability and well production fluctuation was exclude. It is found that the bottom hole pressure of SDJX-A and SDJX-B wells has no obvious production pressure interference and decline phenomenon during the test period, and the bottom hole pressure shows a rising and recovering trend. However, the bottom hole pressure of Sudong X-C well shows a downward trend during the test, and obvious interference phenomenon appears. During the test, the pressure drops by $0.41 \mathrm{MPa}$ from the highest point. It can be judged that there is connectivity between Sudong X-C and Sudong X-A of the exciting well (Fig. 5).

From the geological point of view, only when the well spacing is less than the effective sand body scale can the gas reservoir be fully developed. Through the above method, the connectivity of 29 wells with continuous reservoir and the same production horizon is analyzed by well group. It is found that, based on the current well pattern, except for individual wells, $83 \%$ of production wells have no or poor connectivity. It is confirmed that the effective sand body in SuX area is small in scale and poor in lateral

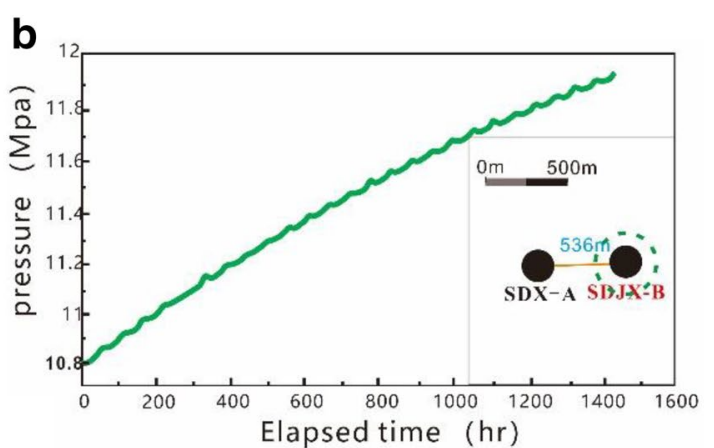

d

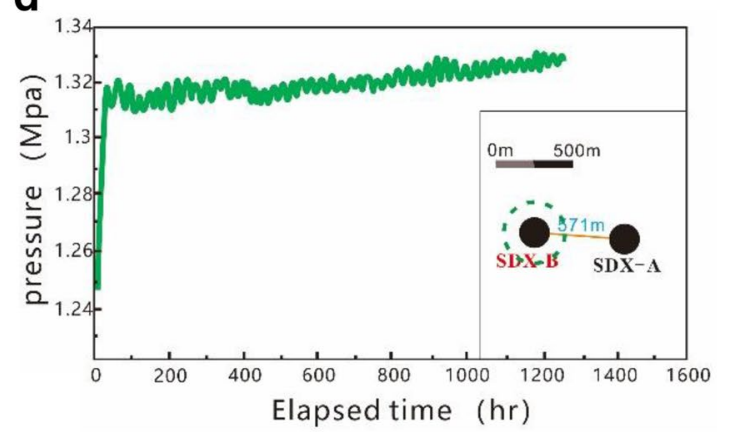

Fig. 5 Measured pressure curve of well cluster SDX-A 
continuity, and it is possible to further infill the well pattern at present.

\section{Analysis of interference degree}

\section{Ional seepage characteristics}

As the low permeability recharge area increases with time, the well-controlled reserves and fluid-release area increase gradually with the extension of production time (Yang et al. 2008). It can be found that the values of several wells with similar production time in the region are characterized by circular area. The well control dynamic reserves and fluidrelease area in 1 year or so of operation are significantly different from those in 5 years of operation, while the well control dynamic reserves and fluid-release areas in 5 years of operation are basically the same as those in 8 years of operation (Fig. 6).

In RTA software, flow material balance method and chart fitting method are used to calculate well control reserves and fluid-release area of production wells in different regions based on half a year. The numerical growth of different blocks is different. Class I wells have obvious growth, long growth duration and obvious difference. The average growth duration required for well control reserves to be stable lasts for 4-6 years. Finally, the production wells with single well reserves less than $4000 \times 10^{4} \mathrm{~m}^{3}$ grow slowly, and the reserves tend to be stable and increase slowly in about 3-4 years of operation. For some class III wells, the production is low, and the fluid-release area grows slowly, which indicates that the low seepage supply capacity of the well leads to the too small gas supply range and the slow growth of its dynamic reserves (Fig. 7).

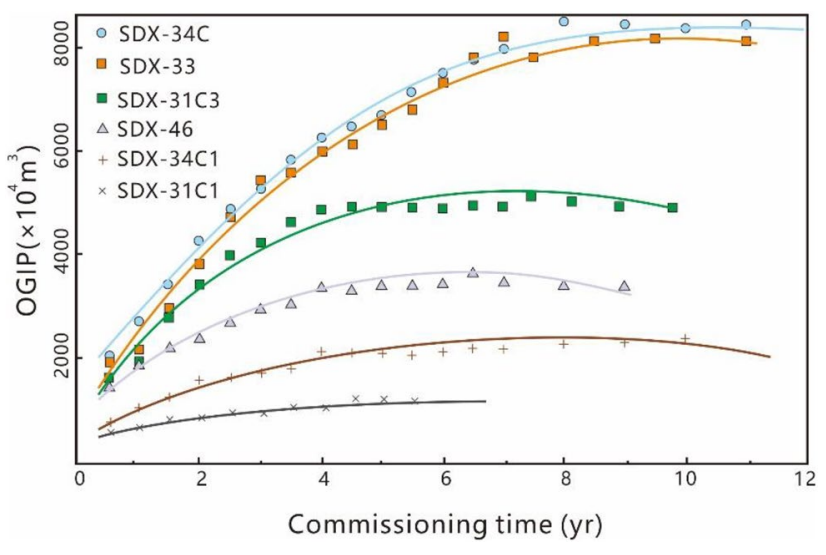

Fig. 7 Change rule chart of well-controlled reserves with time

\section{Well control reserves and well control area calculation}

In view of the percolation characteristics of the above-mentioned low-permeability gas wells, the production wells that have been put into operation for more than 6 years in the test area are selected and calculated by the flowing material balance method. The average well control area of class I wells is $0.39 \mathrm{~m}^{2}$, the average geological reserves are $5710 \times 10^{4} \mathrm{~m}^{3}$; the average well control area of class II wells is $0.27 \mathrm{~km}^{2}$, the average geological reserves are $2510 \times 10^{4} \mathrm{~m}^{3}$; the average geological reserves of class III wells are $2200 \times 10^{4} \mathrm{~m}^{3}$.

The controlled reserves and drainage area of single well in the test area are mainly distributed in $1900-4100 \times 10^{4} \mathrm{~m}^{3}$ and $0.21 \mathrm{~km}^{2}-0.37 \mathrm{~m}^{2}$. Due to the small control range and slow growth of discharge area, it shows that the sand body is small in scale and small in connection range, and there is obvious adjustable space compared with $600 \times 800$ well pattern.
Fig. 6 Fluid-release area a dynamic reserves, $\mathbf{b}$ change chart
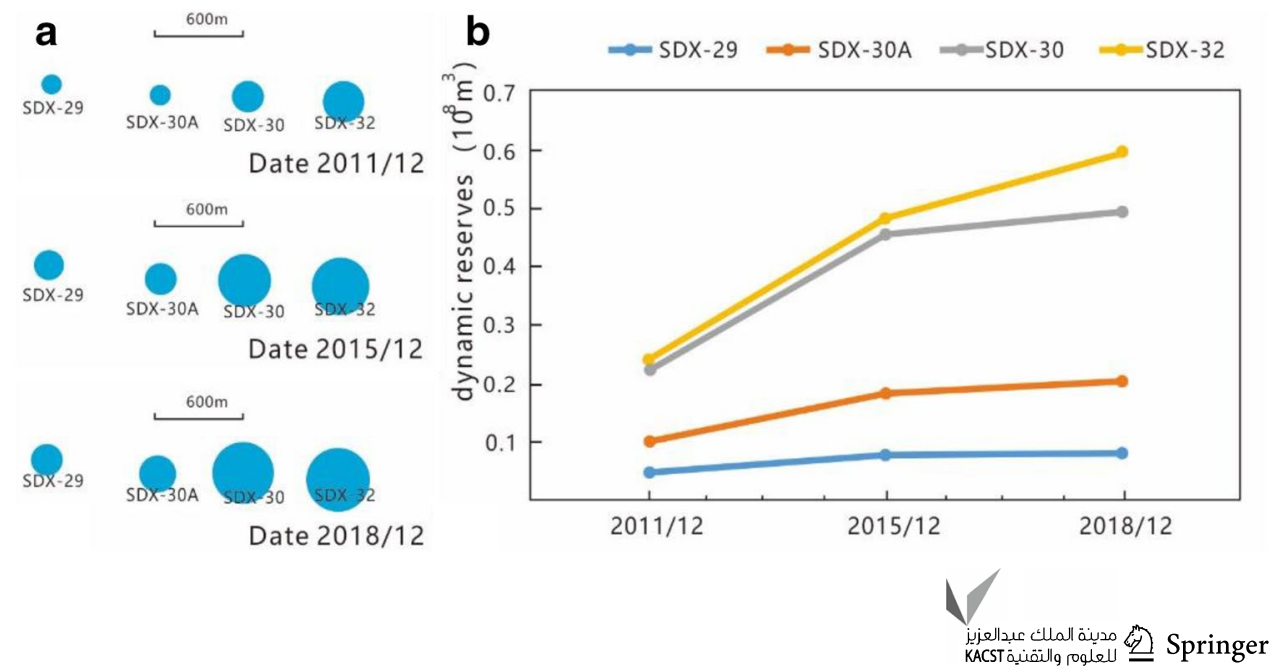


\section{Study on interference degree}

At present, the vertical well pattern of Sulige gas field mainly includes $600 \times 1200 \mathrm{~m}$ and $600 \times 800 \mathrm{~m}$. The interference degree of thin well pattern in the northern area of SuX block is relatively low, and the production pressure funnel of each well is only distributed around the well, and the scope is relatively small. The well pattern density in the southern infill area is large, but the interference degree is not high, which may be related to the short production time of infill wells. Only some production wells have interference, and the data points of Blasingame characteristic curve shift downward after the gas well reaches the radial flow (Fig. 8). Based on the production performance, the interference of production wells with different well spacing is counted. According to the statistical data of modern river sedimentary sand body, the effective sand body length is about $400-700 \mathrm{~m}$, and the width is about $200-500 \mathrm{~m}$ (Table 4).

In order to study the degree of interference between wells after the infilling of the existing well pattern, the average well control area of the infilling block is given to the simulation well by using numerical simulation technology. By using numerical simulation technology to fit the interference degree of different well spacing, it can be concluded that the interference degree between wells decreases with the increase in well spacing. Under the current geological conditions, the interwell pressure interference degree of $400 \mathrm{~m}$ well pattern is high, and the production of wells is seriously affected by the near well interference; the interwell pressure distribution of $500 \mathrm{~m}$ well pattern is relatively uniform, and there is no obvious pressure drop funnel; and when the distance is more than $500 \mathrm{~m}$ and the row distance is more than $600 \mathrm{~m}$, the interference is obviously reduced (Fig. 9). Therefore, it is recommended that the minimum well spacing of infill wells be $500 \mathrm{~m}$. The row spacing shall be controlled at $600 \mathrm{~m}$.

Taking gas production as the key factor to judge the interference, the gas production obtained by non-interference simulation under different well spacing is recorded as $Q_{0}$,
Table 4 Interference statistics

\begin{tabular}{llll}
\hline The well spacing $(\mathrm{m})$ & $\begin{array}{l}\text { Whether the } \\
\text { interference }\end{array}$ & $\begin{array}{l}\text { The degree of } \\
\text { interference }\end{array}$ & $\begin{array}{l}\text { Effective sand } \\
\text { body length } \\
(\mathrm{m})\end{array}$ \\
\hline $\begin{array}{l}\text { Length } \\
<400\end{array}$ & Yes & Strong & $400-700$ \\
$400-600$ & Yes & Medium & \\
$600-800$ & Yes & Weak & \\
$800-1000$ & Yes & Weak & \\
$>1000$ & No & Had no & \\
Width & & & \\
$<400$ & Yes & Strong & $200-500$ \\
$400-600$ & Yes & Weak & \\
$600-800$ & Yes & Weak & \\
$800-1000$ & No & Had no & \\
$>1000$ & No & Had no & \\
\hline
\end{tabular}

which is the theoretical total gas production of a single well. The actual simulated gas production under different well spacing is recorded as $Q_{i}$, which is the actual total gas production of a single well. Then the interference between gas wells in this block can be quantitatively characterized by the single well gas production under different well pattern conditions. The specific formula is as follows:

$$
P\left(1-C \cdot \frac{\sum_{i=1}^{n} Q_{i}}{n Q_{0}}\right)
$$

$P$ interference degree; $C$ well pattern coefficient; $Q_{i}$ well production; $Q_{0}$ undisturbed well production

The data from the numerical simulation results can be calculated by the established interference degree evaluation formula: with the continuous expansion of well spacing and row spacing, the interference degree of two adjacent wells gradually decreases. When the well spacing exceeds $500 \mathrm{~m}$ and row spacing exceeds $400 \mathrm{~m}$, the interference gradually reduces to a reasonable level, that is, under normal
Fig. 8 Change rule of Blasingame characteristic curve with time
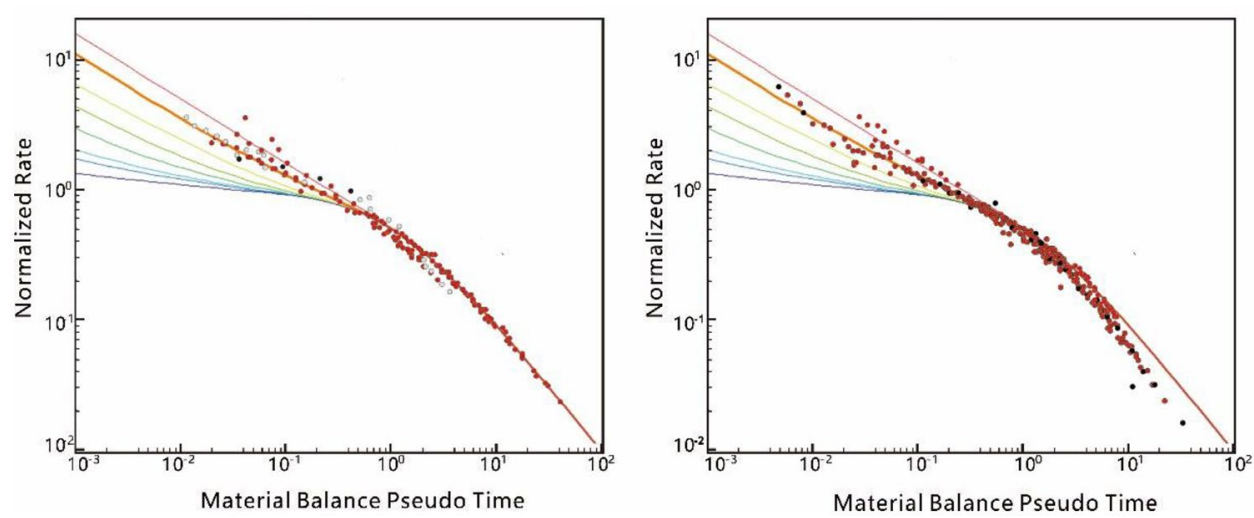

年 KACST 


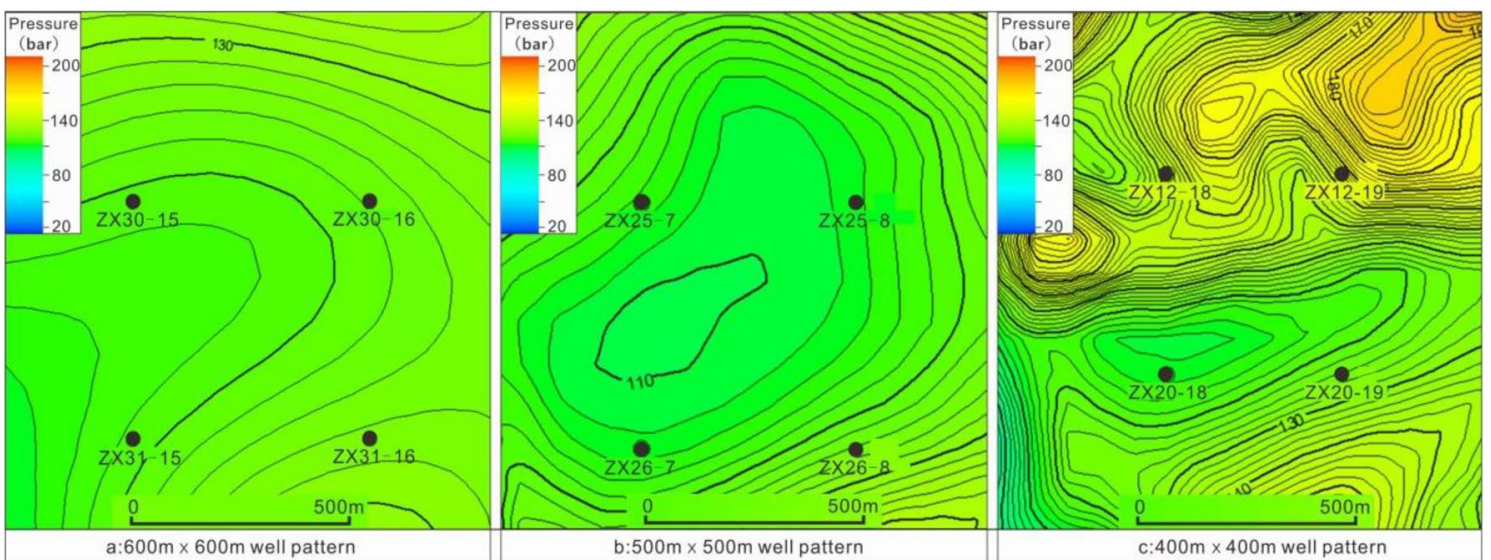

Fig. 9 Analysis diagram of interference degree between wells in different well patterns

Fig. 10 Variation trend of interference degree of different well spacing

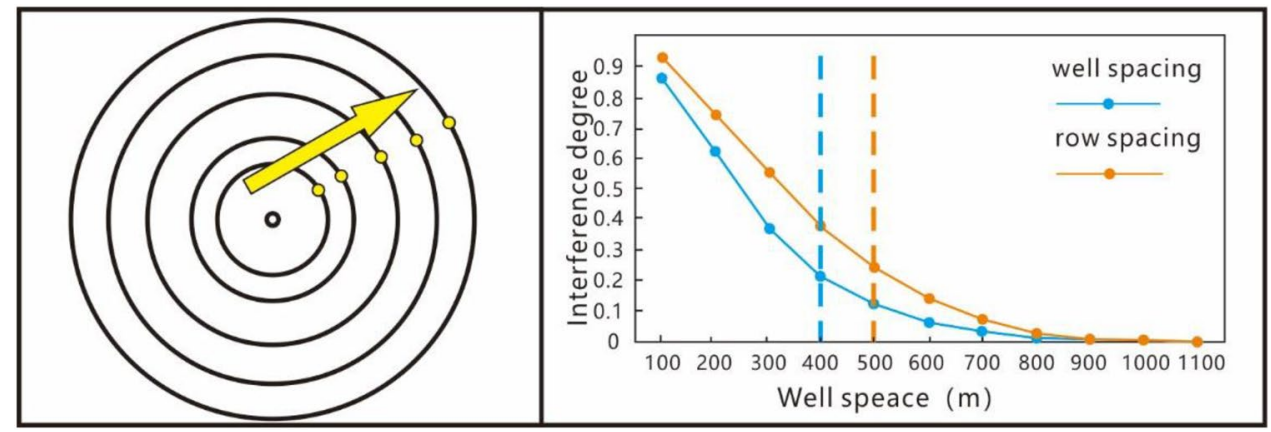

production conditions, the production of two wells does not interfere with each other (Fig. 10).

To sum up, the well pattern distribution in SuX block is quite different at present. The well pattern density in the south is large and the well pattern in the north is sparse. It is suggested that in the later stage of well pattern densification, the local densification method should be adopted. The well spacing should be controlled at about $500 \mathrm{~m}$ and the row spacing should be controlled at $600 \mathrm{~m}$, which can not only maintain a higher well control degree and recovery rate, but also reduce the operation cost and production cost, and improve the internal rate of return.

\section{Conclusion and understanding}

1. In this paper, SDX-A well group in SuX area is taken as an example to determine the interference between wells in the process of gas well production from multiple angles, which proves the rationality of well arrangement after infilling the existing well pattern. In addition, judging the connectivity between wells based on different methods can make the analysis more specific. Due to the long testing time of tight gas reservoir, different methods can determine the connectivity between wells in a more convenient way.

2. It is found that it takes a long time for the fluid-release area and well-controlled reserves to reach stability, and it takes a long time for the gas well seepage to reach the supply boundary. Therefore, the local interference in the south of $\mathrm{SuX}$ is not obvious. There is no obvious interference in the unencrypted area in the North due to the poor physical properties of the reservoir in the block, which proves that there is possibility of local encryption in the block.

3. Using numerical simulation technology to predict different well patterns, it is found that the infilling control of well pattern in the later period is more reasonable within $500 \mathrm{~m} \times 600 \mathrm{~m}$.

4. The findings of this study can help for better understanding of the well pattern infilling and development scheme under the complex geological conditions of tight gas field, and to obtain a more suitable well pattern development mode according to the characteristics of sand bodies in different blocks and the degree of interwell interference. 
Funding This work was supported by the National Natural Science Foundation of China (Grant No. 51504143).

Open Access This article is licensed under a Creative Commons Attribution 4.0 International License, which permits use, sharing, adaptation, distribution and reproduction in any medium or format, as long as you give appropriate credit to the original author(s) and the source, provide a link to the Creative Commons licence, and indicate if changes were made. The images or other third party material in this article are included in the article's Creative Commons licence, unless indicated otherwise in a credit line to the material. If material is not included in the article's Creative Commons licence and your intended use is not permitted by statutory regulation or exceeds the permitted use, you will need to obtain permission directly from the copyright holder. To view a copy of this licence, visit http://creativecommons.org/licenses/by/4.0/.

\section{References}

Amini S, Valkó PP (2010) Using distributed volumetric sources to predict production from multiple-fractured horizontal wells under non-Darcy-flow conditions. SPEJ 15(1):105-115

Fan A, Zhao J, Yang R et al (2011) Pore structure characteristics of Shan 1 and he 8 reservoirs in East 2 block of Sulige gas field. Nat Gas Geosci 22(3):482-487

Fang Q, Chen W, Duan Y (2009) Gas well performance analysis method for tight low permeability gas reservoir. Nat Gas Explor Dev 032(004):40-43

Guang JI, Ailin JI, Dewei ME, Zhi GU, Guoting WA, Cheng L, Xin ZH (2019) Technical strategies for effective development and gas recovery enhancement of a large tight gas field: a case study of Sulige gas field, Ordos Basin, NW China

Guo P, Jing S, Peng C (2014) Technologies and countermeasures for gas recovery enhancement. Nat Gas Ind B 1(1):96-102

He J, Xia H, Zhang H (2003) Calculation and distribution of formation pressure logging in Sulige gas field. Logging Technol Abroad $46: 68-70$
He D, Wang L, Ji G, Wei Y, Jia C (2012) Well spacing optimization for Sulige tight sand gas field, NW China. Pet Explor Dev 39(4):458-464

He D, Jia A, Ji G, Wei Y, Tang H (2013) Well type and pattern optimization technology for large scale tight sand gas, Sulige gas field. Pet Explor Dev 40(1):79-89

Li Q, Wang N, Yi D (2008) Numerical analysis. Tsinghua University Press, Beijing

Mattar L, Anderson DM (2003) A systematic and comprehensive methodology for advanced analysis of production data. In: SPE annual technical conference and exhibition. SPE, Denver, Colorado

Mattar L, Mcneil R (1998) The "flowing" gas material balance. J Can Pet Technol 37(2):52-55

Ren X, Yan Q, He Q (1997) Experimental study on gas seepage characteristics of low permeability gas reservoir. J X'ian Pet Univ (Nat Sci Edn) 3:22

Wang J, Ren Z, Shan J et al (2011) Study on sedimentary system of $\mathrm{He} 8$ and shan 1 members in Eastern Sulige gas field. Geol Sci Technol Inf 30(5):41-48

Yang J, Kang Y, Li Q et al (2008) Microstructure and seepage characteristics of tight sandstone gas reservoir. Progr Mech 02:229-236

Zhang G (2003) Estimating uncertainties in integrated reservoir studies. Dc Language, $p 12$

Zhang M (2010) Evaluation techniques of dynamic reserves: case history of low-permeability and heterogeneous reservoirs in Changqing gas fields. Nat Gas Ind 30(4):50-53

Zhi G, Ailin JIA, Guang JI et al (2017) Reserve classification and well pattern infilling method of tight sandstone gasfield: a case study of Sulige gasfield. Acta Petr Sin 38(11):1299-1309

Zhu L (2015) Study on logging interpretation of Upper Paleozoic tight sandstone gas in Yanqi 2-yan 128 well block of Yan'an gas field. Xi'an Petroleum University

Publisher's Note Springer Nature remains neutral with regard to jurisdictional claims in published maps and institutional affiliations. 